\title{
The Effect of the Heel Wedges on the Electromyography Activities of the Selected Lower Back Muscles During Load Lifting
}

\author{
Mehrdad Anbarian" ${ }^{1 *}$, Fatemeh Rajabian², Mohammad Hossein Ghasemi ${ }^{3}$, Rashid Heidari Moghaddam ${ }^{4}$ \\ 1. Professor, Department of Sport Biomechanics, Faculty of Sport Sciences, Bu Ali Sina University, Hamedan, Iran \\ 2. M.A Student, Department of Physical Education, Islamic Azad University, Borujerdbranch, Borujerd, Iran \\ 3. Ph.D Candidate, Department of Sport Biomechanics, Faculty of Sport Sciences, Bu Ali Sina University, Hamedan, Iran \\ 4. Associate Professor, Department of Ergonomics, School of Public Health and Research Center for Health Sciences, \\ Hamadan University of Medical Sciences, Hamedan, Iran
}

\section{Article Info \\ Original Article \\ Received: 04 Jun 2017; \\ Accepted: 13 Jan. 2018; \\ Published Online 2018/01/23 \\ DOI: $\underline{10.30699 / \text { jergon.5.3.12 }}$}

Use your device to scan
and read the article online

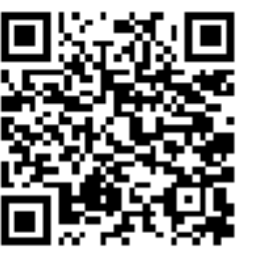

Corresponding Author

Mehrdad Anbarian

Professor, Department of

Sport Biomechanics, Faculty

of Sport Sciences, Bu Ali

Sina University, Hamedan,

Iran

Email:

anbarian@basu.ac.ir

\section{ABSTRACT}

Background: The aim of this study was to investigate the effect of the heel wedges on the electromyography activities of the selected left and right lower back muscles during load lifting.

Methods: A total of 17 male subjects voluntarily participated in this quasiexperimental study. The selected subjects lifted a box, weighing $10 \%$ of their body weight, above the height of their hip joint, descending as far as the thigh, parallel to the ground, and then ascending to the starting position. The above task was performed nine times in two conditions, including with and without the heel wedges. Using the ME6000 electromyography system, the activity level variables were normalized and the median frequencies of the erector spinae (ES) and the multifidus (MU) muscles were recorded. The subjects also held the box for $30 \mathrm{~s}$ in the standing position with stretched hands. The paired t-test was used for the data analysis.

Results: The results showed that during static load lifting using the heel wedge, the median frequency of the right ES muscle changed significantly $(\mathrm{P}<0.05)$. Also during dynamic load lifting using the heel wedge, the activities of the left and the right ES muscles as well as the left MU muscle decreased significantly $(\mathrm{P}<0.05)$. However, no significant differences between the two conditions were observed for the other variables $(\mathrm{P}>0.05)$.

Conclusion: During such occupational tasks, a decrease in the activities of the selected lower back muscles with the heel wedge might result in a delay in the onset of muscle fatigue. The above findings might be used in the design of shoes, suitable for the work environments. However, further investigations are needed in this area in order to provide more accurate results.

Keywords: Heel Wedge; Electromyography Activity; Load Lifting; Erector Spinae Muscles

Copyright $\odot$ 2018, Journal of Ergonomics. This is an open-access article distributed under the terms of the Creative Commons Attribution-noncommercial 4.0 International License which permits copy and redistribute the material just in noncommercial usages, provided the original work is properly cited.

\section{How to Cite This Article:}

Anbarian M, Rajabian F, Ghasemi M H, Heidari Moghaddam R. The Effect of the Heel Wedges on the Electromyography Activities of the Selected Lower Back Muscles During Load Lifting. J Ergon. $2018 ; 5$ (3) :1221 


\section{مقالهُ يزوهشى}

تأثير كَوة ياشنه بر فعاليت الكترومايوكرافى عضلات منتخب ناحيةً كمر، هنغام بلندكردنِ بار

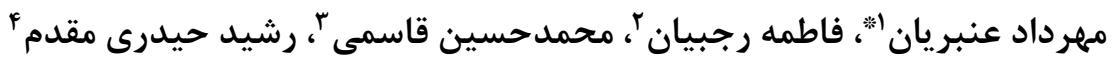

I. استاد، گروه بيومكانيك ورزشى، دانشكدة علوم ورزشى، دانشگاه بوعلى سينا، همدان، ايران

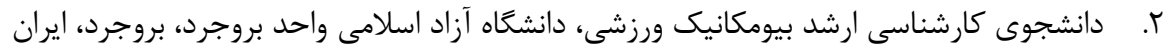

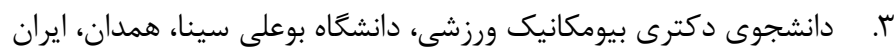

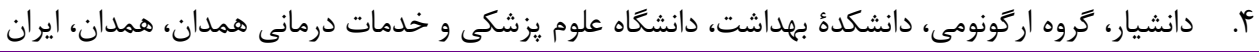

\begin{tabular}{|c|c|}
\hline خلاصه & اطلاعات مقاله \\
\hline 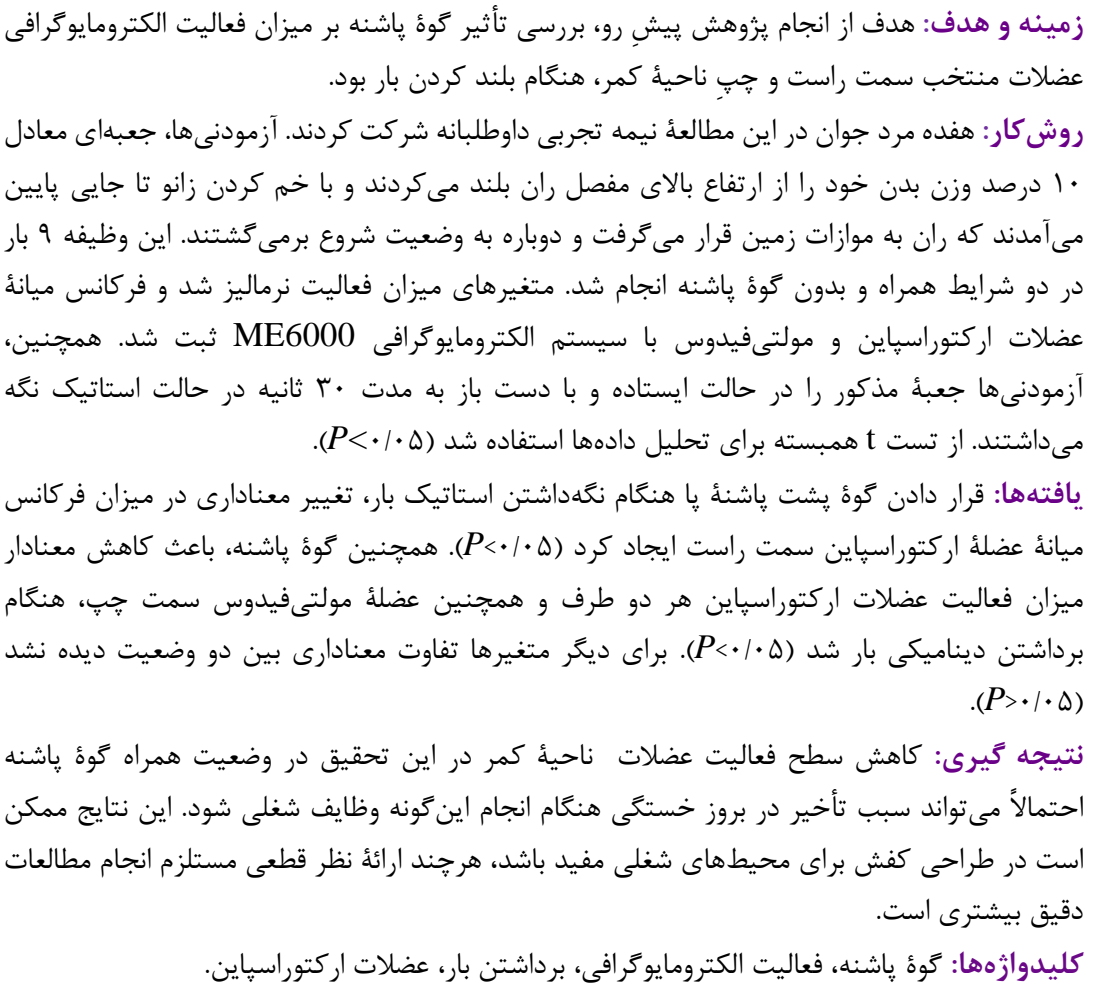 & 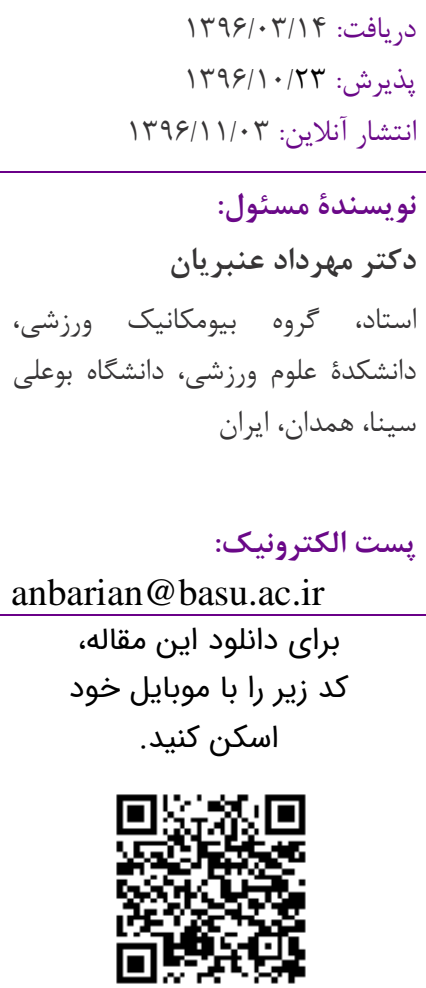 \\
\hline
\end{tabular}

مقدمه

اركتوراسياين، وزن بار و و تكرار حركت معى متواند فشار

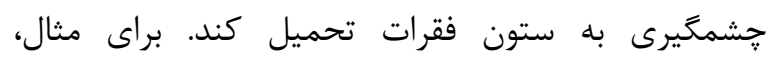
Rohlmann جايخزينى مهرههاى داراى سيستم تلمترى در بدنِ بيمارانى

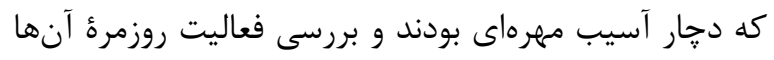

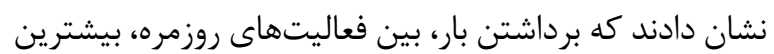

$$
\text { فشار را به ستون فقرات وارد مى كند [ه]. }
$$

در بسيارى از كارخانههاى دنيا، رعايت اصول ايمنى و واتودئ برداشتن صحيح وزنهها، جزئى از آموزشهاى اوليهاى هستند كه بايد در محيط كار رعايت شوند [ع]. باينحال، مطالعات مرورى اخير حكايت از ناكارآمدى آموزش فنِ صحيح ليفت يا
با اينكه در دنياى امروزى بسيارى از فرايندها مكانيزه شدهاند؛ اما هنوز در صنايع مختلف كارهاى زيادى بهصورت دئ دئي

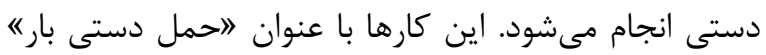

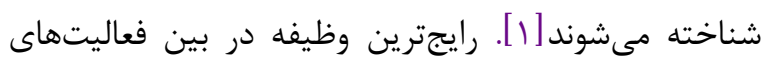
حمل دستى بار در محيطهاى شغلى، بلند كردن بار است كه به مىتواند سبب ايجاد اختلالات اسكلتى ـ عضلاني مرتبط با كار

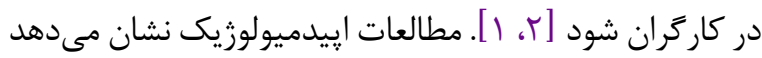
كه بروز كمردرد در محيطهاى شغلى يكى از رايجترين

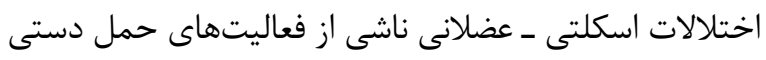

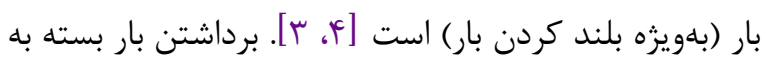

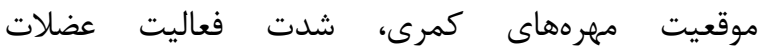


يكى از مهممترين گروه عضلات ناحية خلفى تنه، عضلات

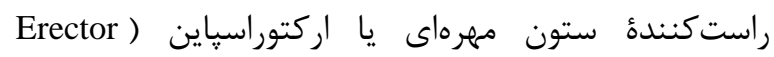

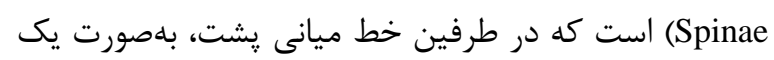
توده عضلانى قرار كرفته است و در طول ستون مهرهاى، از جمجمه تا ساكروم، امتداد دارد و عمل اكستنشن ستون فقرات

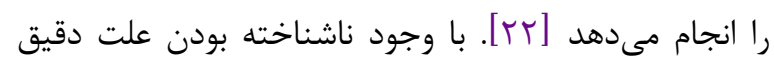
ايجاد كمردرد [بrr]، يكى از دلايل ايجاد اين عارضه، يعنى

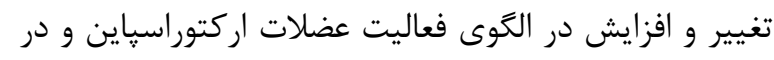
نتيجه افزايش بارهاى وارده بر مفاصل اين ناحيه همواره توجه

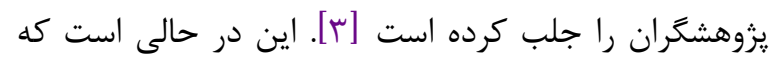
روش درست برداشتن بار مىتواند باعث كاهش انرزى مصرفى ردئ

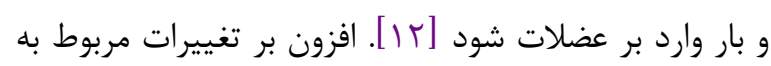

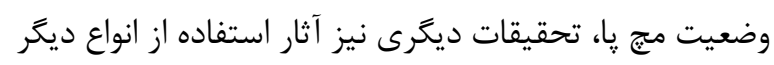

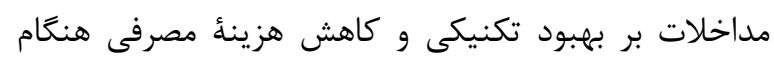
انجام وظايف كارى را بررسى كردهاند. Abdoli و Stevenson

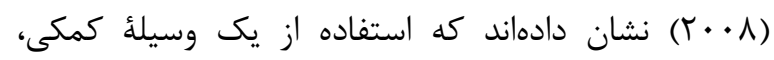
كشتاورهاى ناشى از وزن بار بر ستون مهرهها را كاهش مهىدهد و سبب كاهش فعاليت عضلات اركتوراسياين و افزايش فعاليت

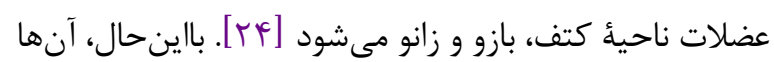

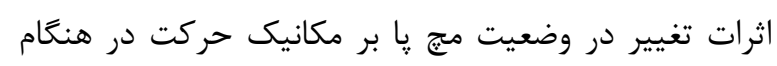
برداشتن بار را بررسى نكردهاند.

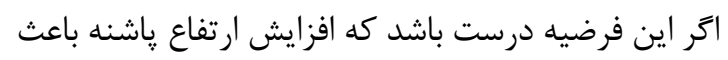
تغيير در عملكرد عضلات درگير هنغام انجام وظايف كارى مىشود، يرسش مطرح شده اين است كه آيا تغيير در وضعيت

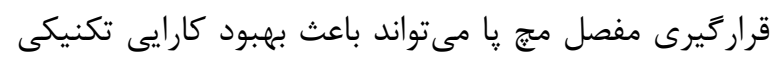

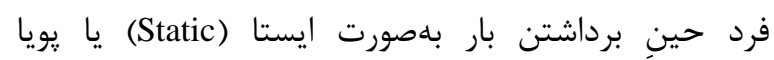

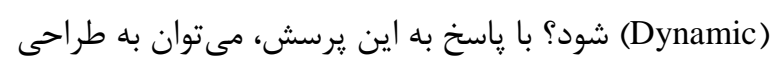

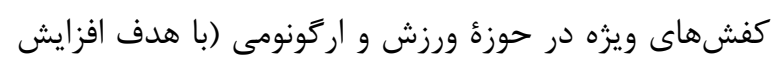

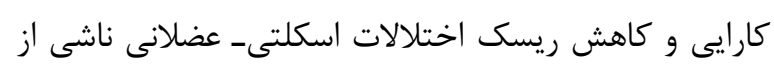

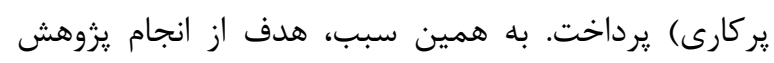

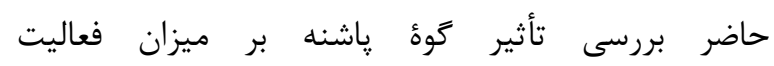

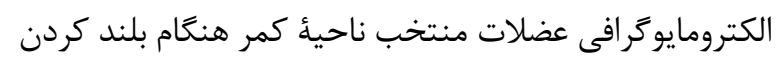

بار بود.
بلند كردن بار به افراد براى ييشخيرى از بروز كمردرد دارند

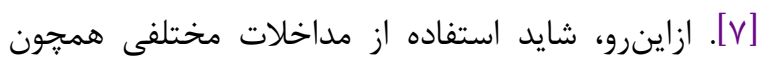

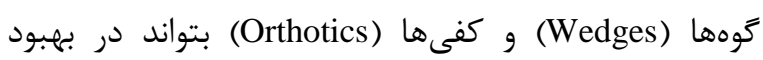
عملكرد حركتى افراد در محيطهاى شغلى سودمند باشد. كفى ها و گوهها وسايلى هستند كه براى تكميل سطوح اتكاى

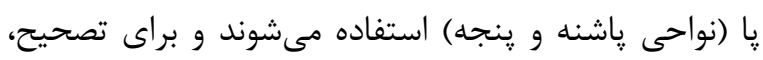
تغيير شكل، جلوگيرى يا بهبود ناهنجارىهاى مختلف ناحئ

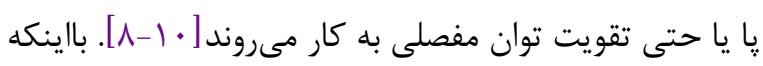

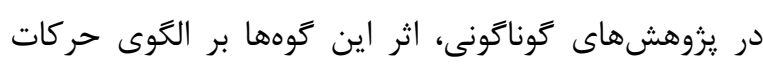

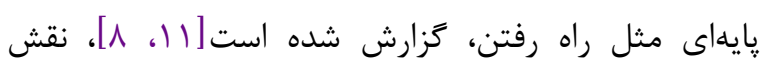

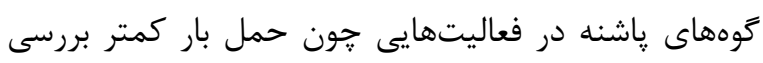

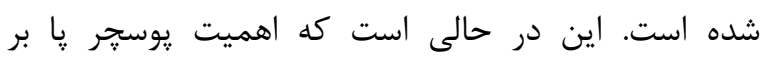

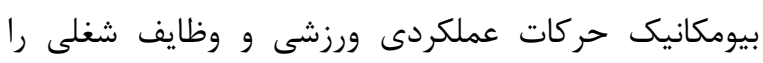

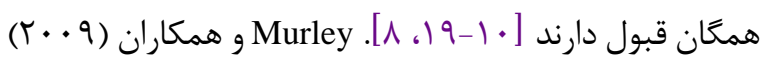
در يك مطالعهُ مرورى بيان كردند كه يوسجر و ناهنجارىهاى

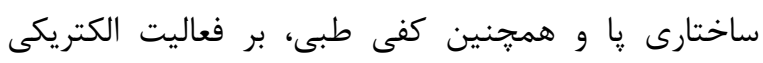
عضلات اندام تحتانى و كمر مؤثر هستند [ • [1]. برداشتن بار با استفاده از تكنيك اسكات (Squat) در زمرة حركات زنجيره حركتى بسته است. درنتيجه وضعيت يكى بار بـن مفصل هنغام اجراى اين تكنيك، بر حركت مفاصل ديخر

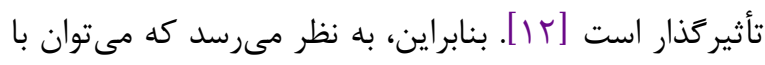

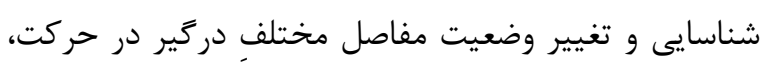
به تغيير در ميزان فعاليت اين عضلات دست يافت تا از اين طريق بتوان به اهدافى نظير ايمنى شغلى، بيشخيرى از

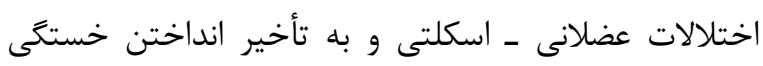
عضلانى (موضعى) در محيط شغلى نزديك شد. به همين منظور، در تحقيقات ييشين موقعيتهاى مختلف مج ياها

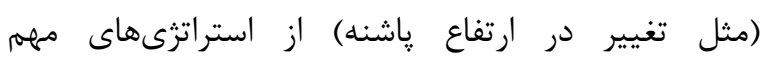

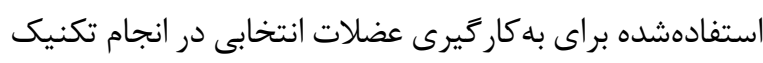

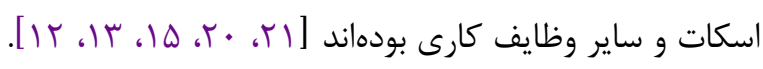

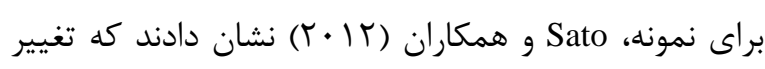
موقعيت مج پا به سمت يلانتارفلكشن (Plantar Flexion)

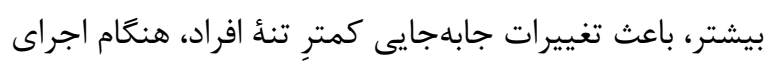
اسكات مىشود و اين وضعيت به كاهش خطر ابتلا به صدمات

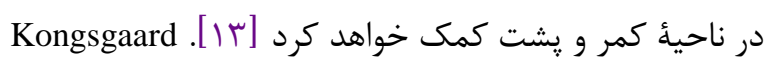

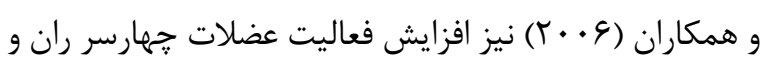
خستخى زودرس آنها را هنغام افزايش ارتفاع ياشنه تزارش

كردند [rا 
هرتز جمعآورى شدند. همجنين، از يك الكتروگونيامتر

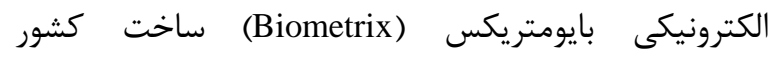

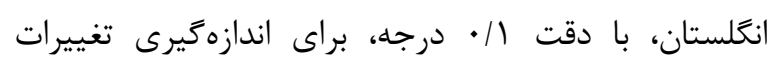
زاويهاى مفصل زانو استفاده شد.

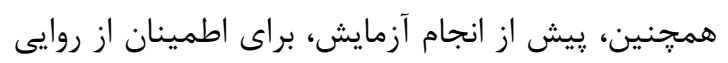

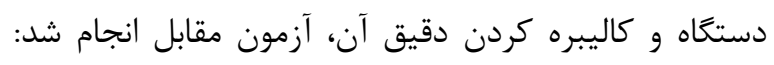

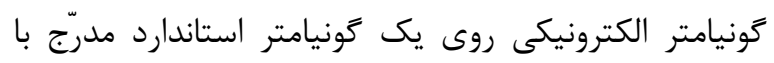
دقت يكدهم درجه قرار خرفت؛ بلهنحوى كه بازوى كونيامتر

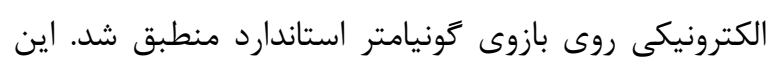

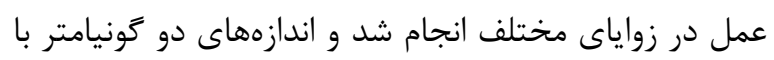

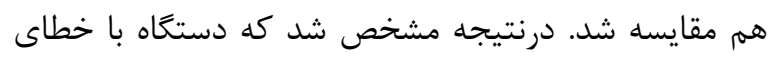

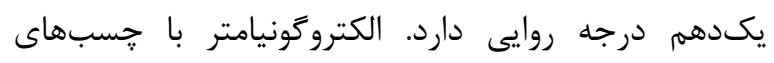

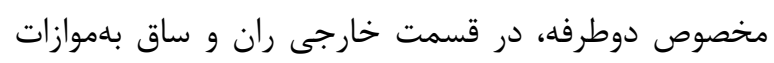

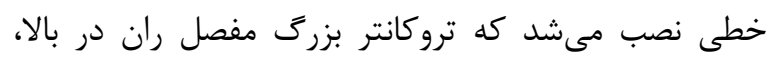

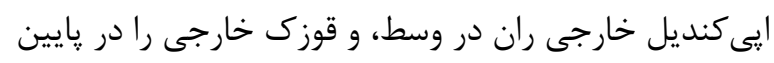

به هم وصل كند [عr].

\section{روش انجام وظايف آزمودنى}

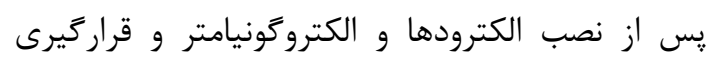
آزمودنى در وضعيت شروع، از آزمودنى خواسته شد آند تا وظايف

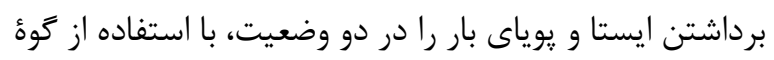

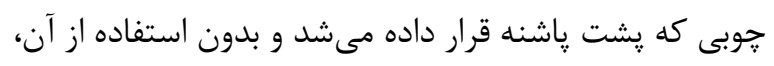

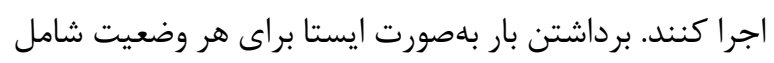

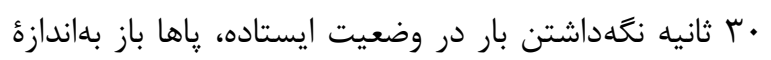

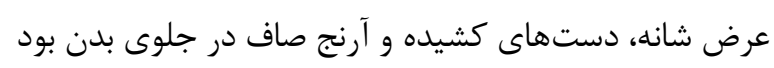

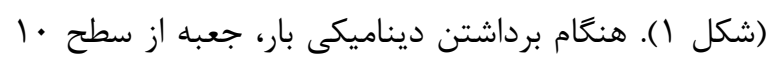

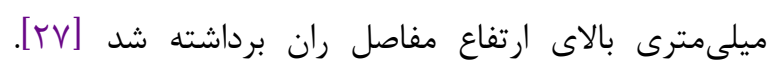

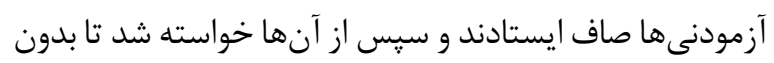

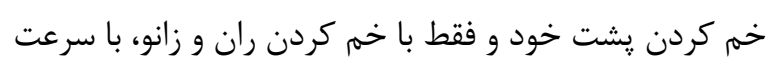

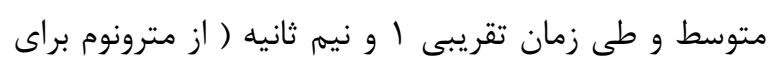

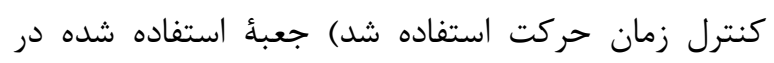

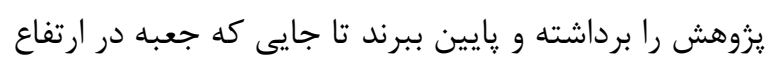

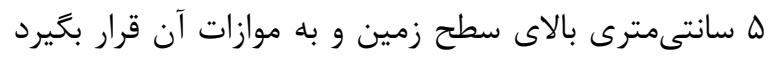

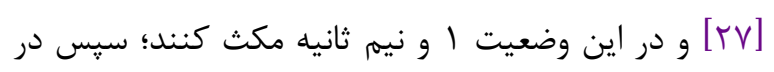

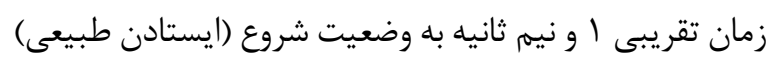

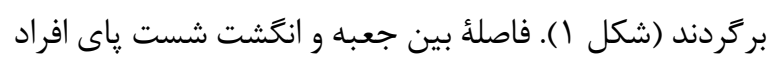
موقع رسيدن جعبه به نزديكى سطح زمين حدوداً له سانتى متر

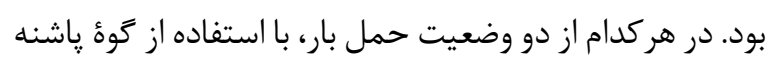

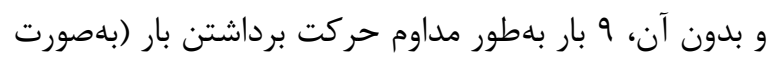


وزن جعبئ استفادهده برابر • 1\% وزن هر آزمودنى در نظر

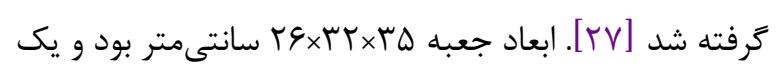
دسته در هر طرف داشت كه در فاصلئ IV سانتى مترى بالاى

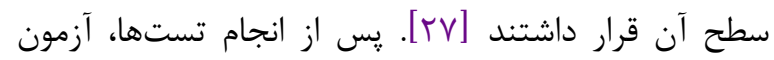

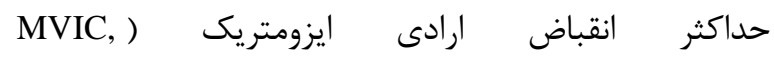
(MaximumIsometric Voluntary Contraction عضلات ناحية كمر (براى نرماليز كردن دادههاى عضلات در وضعيتهاى مختلف) انجام شد. براى انجام اين آزمون، آزمودنى، روى ميز به شكمى دراز مى كشيد، درحالى كه تنه و

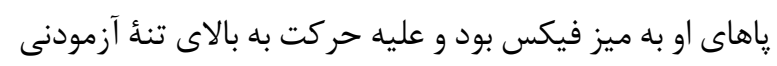
(كشش يا اكستنشن تنه) مقاومت اعمال مىشد.

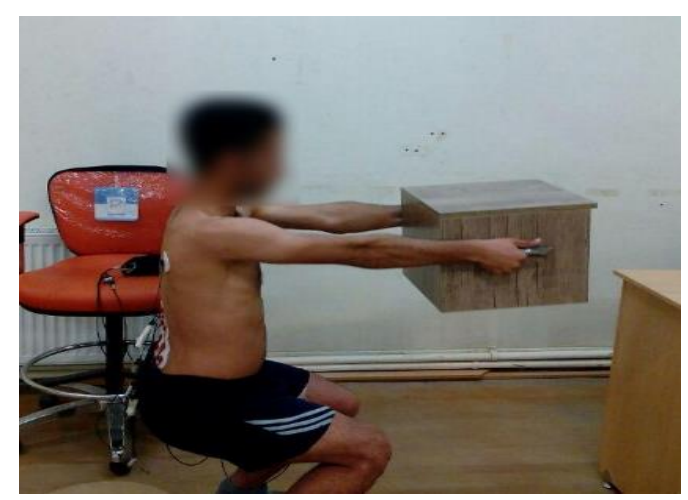

محاسبه و در دو وضعيت همراه و بدون زوه پاشنه مقايسه شد.

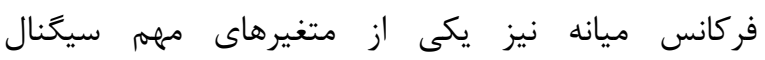
الكتروميوكرافى در حوزه فر كانس است و با سرعت هدايت در بافت عضلانى و نرخ كدگذارى (كه يكى از مكانيزمهاى افزايش

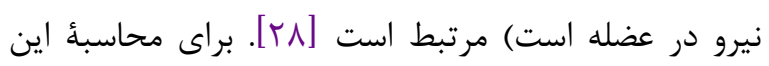

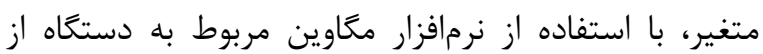
سيخنال هاى خام الكتروميوگرافى با برنامة آناليز طيف تبديل سريع فورير در بازه زمانى كل حركت استفاده شد. اين شاخص

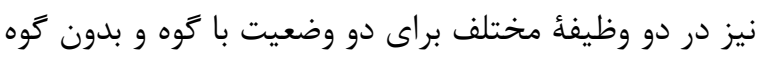
محاسبه شد.
موفق) انجام شد و ميانگين متغيرهاى مربوط، در ه حركت

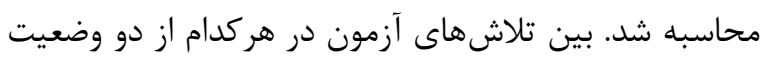
(همجنين بين تعويض آزمونها از حالت نكهداشتن ايستا به حالت برداشتن يويا)، دستكم • دم دقيقه به آزمودنىها استراحت داده مىشد تا خستخى انجام تست برطرف شود. نحوه انجام آزمونها نيز در وضعيتهاى با گوهُ ياشنه و بدون آن، بهصورت تصادفى بود تا اثر يادكيرى و ترتيب اجراى آزمون روى دادههاى ثبتشده خنثى شود. گَوه استفادهده

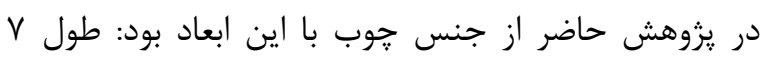

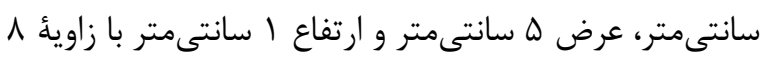

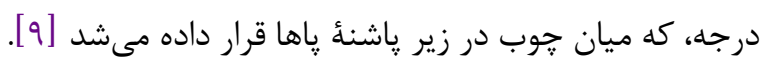

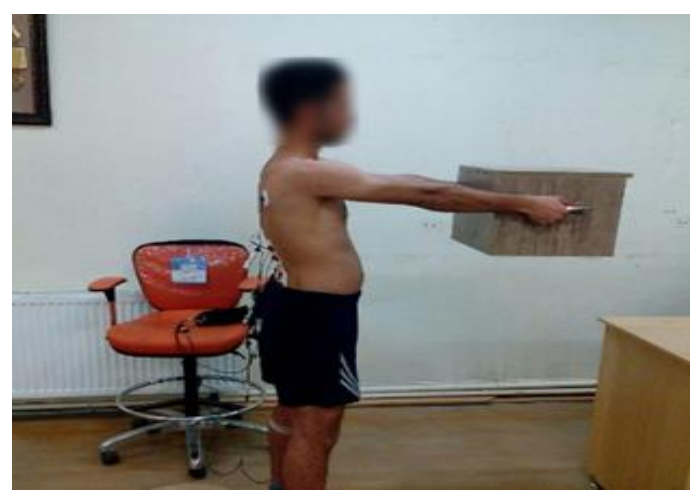

شكل ا. نحوه قرارئرى آزمودنىها براى انجام آزمايشها

\section{تجزيهو تحليل دادهها}

سيخنال هاى خام از فيلتر ميان خذر • له- • هرتز عبور داده شد. مقدار Root Mean Square) RMS) با ثابت زمانى ه • • • ثانيه در بازه زمانى كل حركت برداشتن بار و • • ثانيه نحهدداشتن ايستاى بار براى هر عضله محاسبه شد و اين مقادير بر مقدار حداكثر RMS در آزمون MVIC همان عضله تقسيم ئنس و سيس در عدد . ا ضرب شد. بازه زمانى كل حركت برداشتن بار با استفاده از دادههاى الكتروگونيامتر بهطور دقيق مشخص و جداسازى مىشد (شكل ب). درنهايت، فعاليت نرماليز شده عضله بهعنوان درصدى از حداكثر فعاليت عضله 


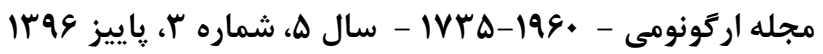

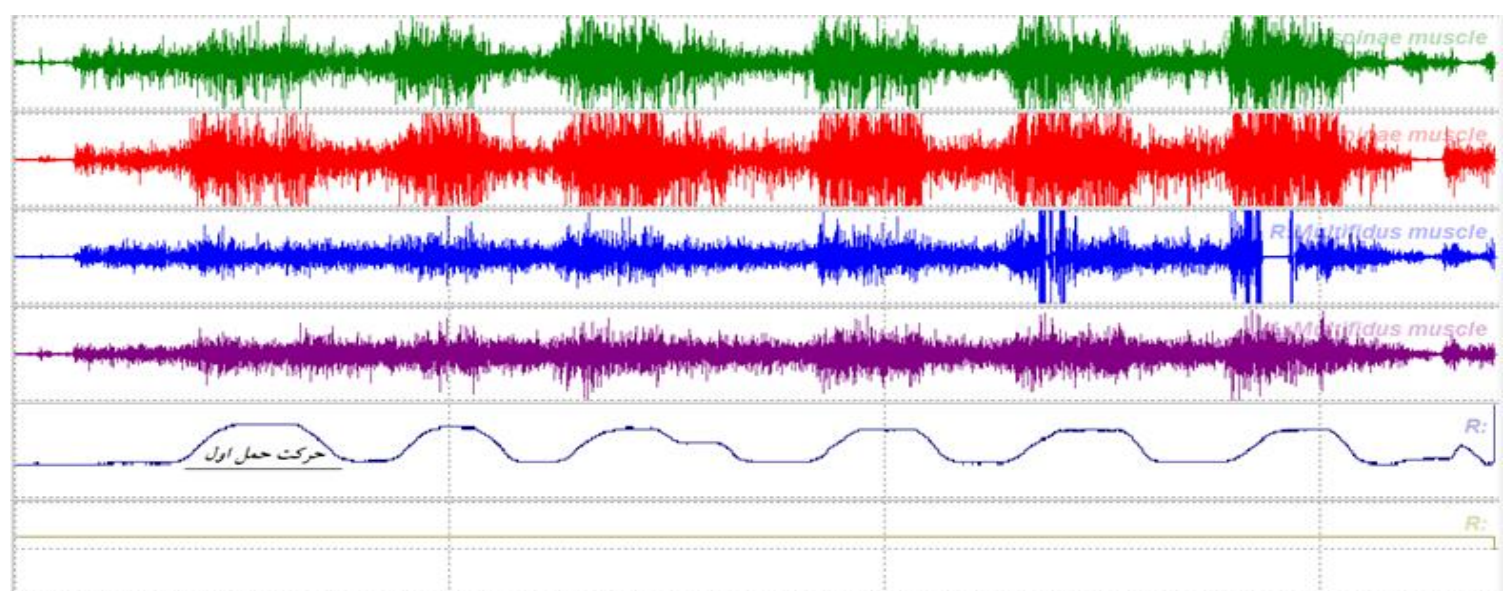

شكل r. تشخيص زمان آغاز و پايان هر حركت حمل بار و نحوه دقيق جداسازى با استفاده از دادهاى الكتروكونيامتر

بين دو وضعيت بدون گوه و با گوه، اختلافى در ميزان

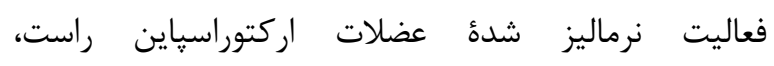

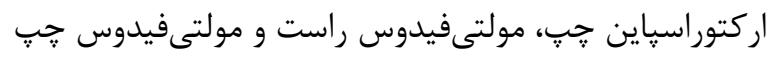

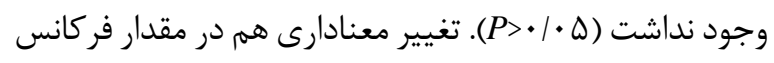

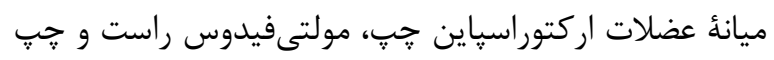

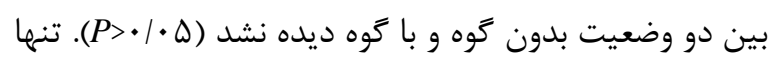
تغيير معنادار مشاهدهده، مربوط به ميزان فركانس ميانه

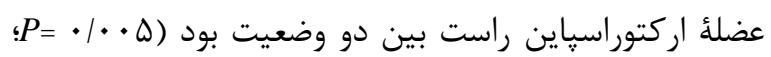

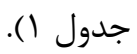

روش تحليل آمارى براى تحليل آمارى، از نرمافزار SPSS نسخئ عاى استفاده شد. براى بررسى نرمال بودن توزيع دادها از آزمون شاييرو ـ

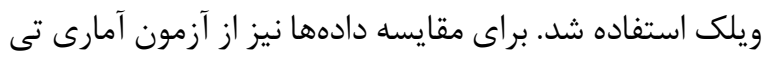
ـ تست وابسته استفاده شد و سطح معنادارى در تمامى آزمونها برابر ه • • • در نظر گرفته شد.

بافتهها

مقايسةُ متغيرهاى الكتروميوكرافى عضلات ناحية

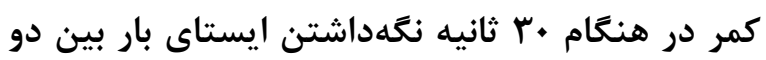

\section{وضعيت با توه و بدون گَوه}

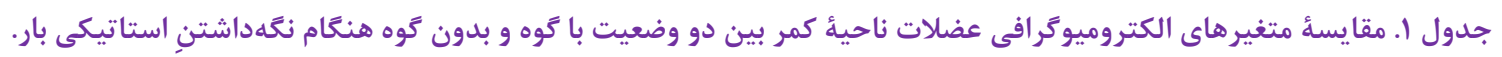

\begin{tabular}{|c|c|c|c|}
\hline مقدار P & با كَوهُ ياشنه & بدون تَوه باشنه & متغير \\
\hline.$/ \cdot 9 \vee$ & $\cdot|r| \pm \cdot / \cdot \Lambda$ & $\cdot / 19 \pm \cdot / \cdot 1$ & ميزان فعاليت نرمالايز شدة اركتوراسياين راست (برحسب درصد از \\
\hline$\cdot$ r TAF & $\cdot / r t \pm \cdot / \cdot \wedge 9$ & $|r| \pm \cdot / \cdot 9$ & ميزان فعاليت نرمالايز شده اركتوراسياين جِ (برحسب درصد از \\
\hline$\cdot / T V K$ & $\cdot / T \omega \pm \cdot / 1$ & $\cdot / K F \pm \cdot / \cdot 9$ & ميزان فعاليت نرمالايز شده مولتىفيدوس راست (برحسب درصد از \\
\hline$\cdot / T Y V=$ & $\cdot|r| \pm \cdot / \mid r$ & $\cdot / r 9 \pm \cdot / 11$ & ميزان فعاليت نرمالايز شدهٔ مولتىفيدوس جِ (برحسب درصد از \\
\hline$* \cdot \cdot \cdot \Delta$ & SV/VG $\pm 11 / 9$ & $V T / 9 D \pm I F / V$ & ميزان فر كانس ميانهُ اركتوراسياين راست (هرتز) \\
\hline$\cdot 194 \Lambda$ & $V T / A V \pm I r$ & $V T / Y F \pm I F / D$ & ميزان فركانس ميانهُ اركتوراسياين جٍِ (هرتز) \\
\hline$\cdot / \Delta \wedge \Lambda$ & $119 / 1 \pm 18 / 1$ & $\| V / F \pm r \cdot / 1$ & ميزان فركانس ميانهٔ مولتىفيدوس راست (هرتز) \\
\hline$\cdot \mid \Delta \& V$ & $119 / 1 \pm 19 / 9$ & $\| \varepsilon / 4 \pm r r / r$ & ميزان فركانس ميانهُ مولتىفيدوس جب (هرتز) \\
\hline \multicolumn{4}{|c|}{$\boldsymbol{P}<\bullet / \bullet \Delta^{*}$} \\
\hline
\end{tabular}


مهرداد عنبريان و همكاران | تأثير تؤُ ياشنه بر فعاليت الكترومايوكرافى...

وجود دارد؛ اما تغيير معنادارى در ميزان فعاليت عضله مولتىفيدوس راست بين دو وضعيت ديده نشد

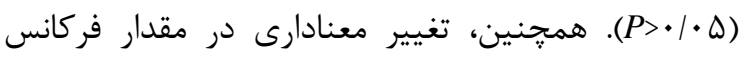

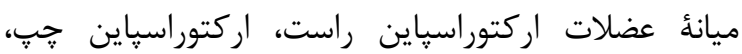
مولتىفيدوس راست و مولتىفيدوس جٍٍ بين دو وضعيت

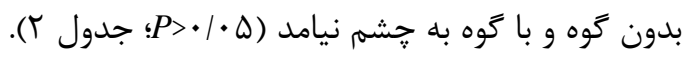

مقايسةُ متغيرهاى الكتروميوگرافى عضلات ناحيةٌ كمر بين دو وضعيت با َّوه و بدون گَوه هنًَام برداشتن ديناميكى بار نتايج آزمون آمارى t وابسته نشان داد كه بين دور

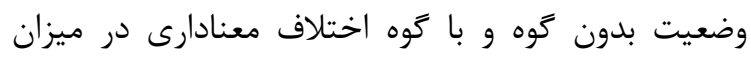

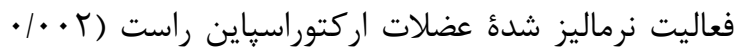
P=

جدول r. مقايسُٔ متغير هاى الكتروميوكرافى عضلات ناحيةُ كمر بين دو وضعيت با كَه و بدون گَوه هنعَام برداشتن ديناميكى بار.

\begin{tabular}{|c|c|c|c|}
\hline Pقدار P P & با كَوهُ باشنه & بدون كَوه هاشنه & 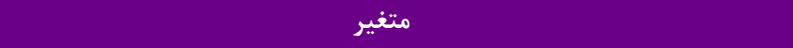 \\
\hline$* / \cdot r$ & ( & ( & ميزان فعاليت نرمالايز شده اركتوراسياين راست (برحسب درصد از فعاليت \\
\hline سr & $\cdot / 49 \pm \cdot 111$ & $\cdot / 19 \pm \cdot / 11$ & ميزان فعاليت نرمالايز شدهُ اركتور اسياين جٍ (بر حسب درصد از فعاليت \\
\hline$\cdot / 4 r \Delta$ & $\cdot / \kappa \varphi \pm \cdot / r \Delta$ & $\cdot|\Delta \cdot \pm \cdot| r \mid$ & ميزان فعاليت نرمالايز شدهٔ مولتىفيدوس راست (برحسب درصد از فعاليت \\
\hline$* 1 \cdot \cdot 1$ & $\cdot / 4 T \pm \cdot / 1 r$ & $\cdot / \& V \pm \cdot / 1 \Delta$ & ميزان فعاليت نرمالايز شدهُ مولتىفيدوس جب (برحسب درصد از فعاليت \\
\hline$\cdot / T V \Delta$ & $9 Y / \cdot 9 \pm 1 \cdot 11$ & $91 / \pi T \pm 9 / 9$ & ميزان فركانس ميانهُ اركتوراسياين راست (هرتز) \\
\hline.$/ \pi r s$ & $9 \cdot 19 T \pm N / V$ & $\Delta q / \Upsilon \varphi \pm \Lambda / V$ & ميزان فركانس ميانهُ اركتور اسِياين حٍ (هرتز) \\
\hline$\cdot / 11$ & $9 \Delta / 1 \Gamma \pm 11 / 1$ & $9 \Lambda / 9 \Delta \pm 1 T / V$ & ميزان فر كانس ميانهٔ مولتىفيدوس راست (هر تز) \\
\hline$\cdot / \vee 9 \wedge$ & $91 / f \Delta \pm 19 / 9$ & $q \cdot / 99 \pm r \cdot / r$ & ميزان فركانس ميانهُ مولتىفيدوس جٍٍ (هرتز) \\
\hline & & & $P<\cdot 1 \cdot \Delta^{*}$ \\
\hline
\end{tabular}

يكى از مهمترين عوامل اثركذار بر متغيرهاى بيومكانيكى و عملكرد عضلانى حين حركت اسكات است كه در مطالعات ييشين در حوزه ورزشى و توانبخشى نيز بدان توجه شده

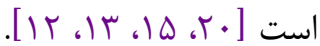
با اينكه يزوهشهاى متعددى در اين زمينه انجام شده است، نَارند ₹ان مقالهٔ حاضر، مطالعهاى نيافتهاند كه اثر گَوه هاى ياشنه بر فعاليت الكتروميوگرافى عضلات دوطرفئ ستون

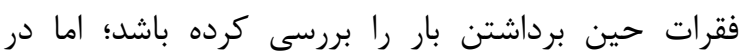

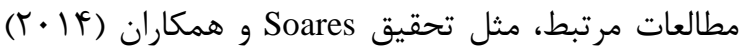

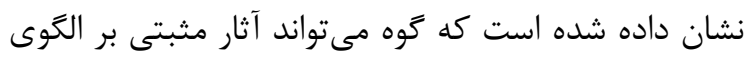
بيومكانيكى راه رفتن داشته باشد [^]. همجنين، Sato و و

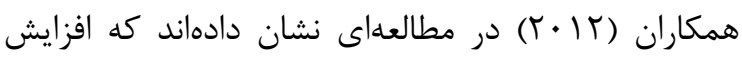
ارتفاع ياشنه و ايجاد يلانتارفلكشن در مج ياها باعث تغييرات

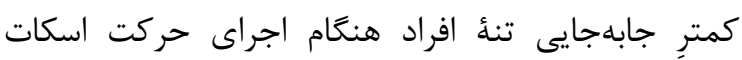

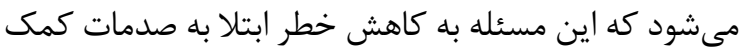

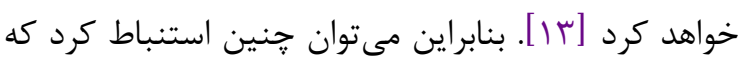

\section{بحث و نتيجه تيرى}

نتايج مطالعهُ پيش رو نشان داد كه استفاده از گوه تغييرى در ميزان فعاليت عضلات اركتوراسياين و و مولتىفيدوس راست و جֶٍ هنگَام نحهداشتن استاتيك بار

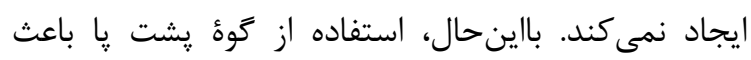
كاهش معنادار ميزان فعاليت عضلات اركتوراسياين راست و و

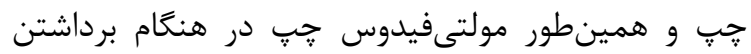
ديناميكى بار شد. براى توضيح تغييرات ايجادشده، ذكر مورئ

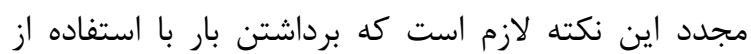
تكنيك اسكات، جزء حركات زنجيره حر كتى بسته محسوب مىشود و حين اجراى اين تكنيك، وضعيت يك مفصل بر

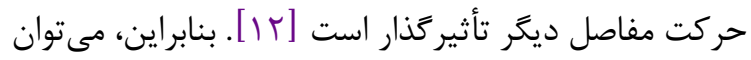

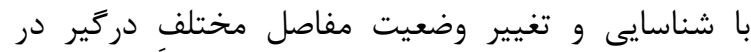
حركت، به تغيير در ميزان فعاليت عضلات درگير در حركت

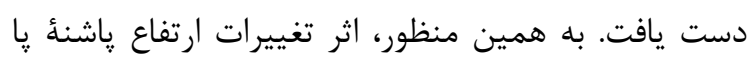


داشتند. اگرجه مطالعههاى Trifimow و همكاران (T99 ()

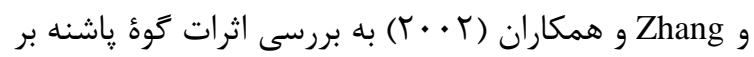

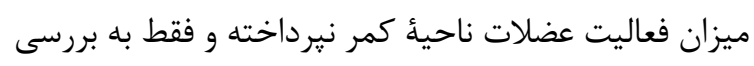

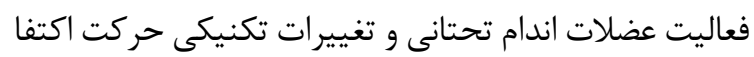

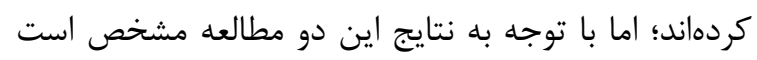
كه كاهش فعاليت عضلات اصلي درگير حين برداشتن بار مىتواند به خستخى ديرتر، تداوم استفاده از تكنيك اسكات

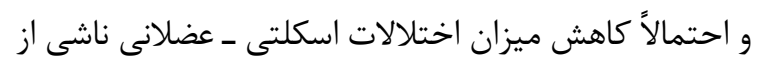

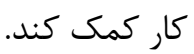

افزون بر تغييرات مربوط به وضعيت مج ڤا، تحقيقات

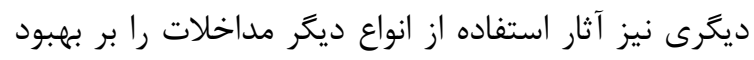

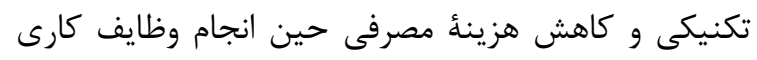

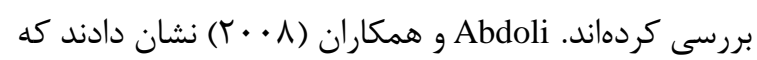

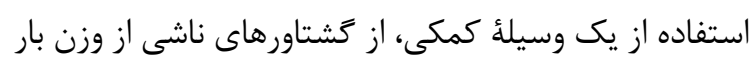
بر ستون مهره مى كاهد و باعث كاهشي ميزان فعاليت عضلات

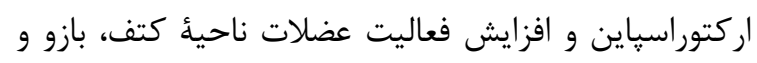
زانو مىشود [rT]

استفاده از زوه ڤِاشنه تنها تغيير معنادارى در ميزان فركانس ميانٔ عضلات اركتوراسياين راست حين نحهداشتن ايستاى بار ايجاد كرد. هنغام برداشتن ديناميكى بار، تغيير

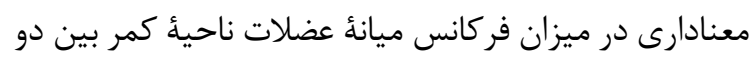

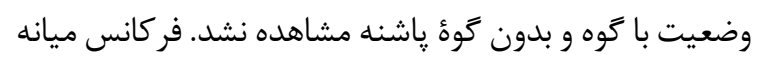

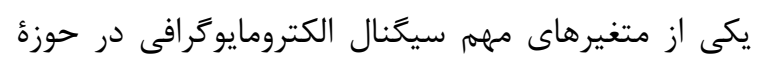

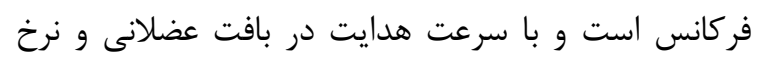
كدَذارى (كه يكى از مكانيزمهاى افزايش نيرو در عضله

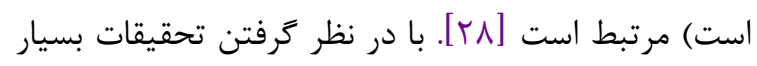

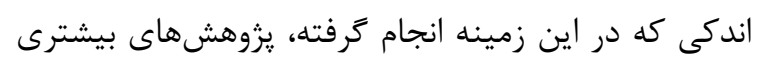

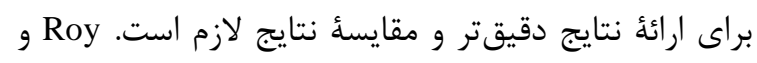

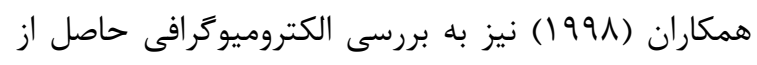

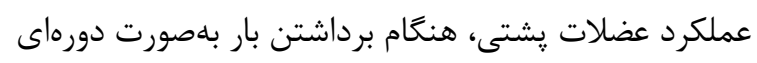

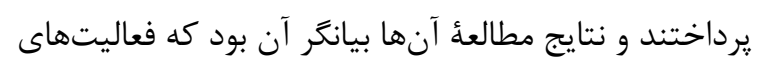

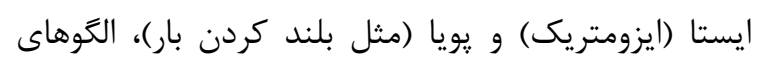

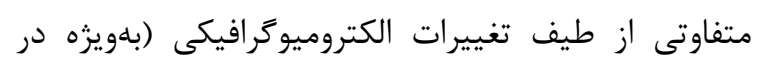
مقادير MPF) نشان مىدهند و اين مىتواند به دليل متفاوت

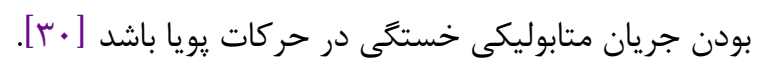

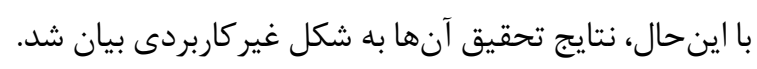

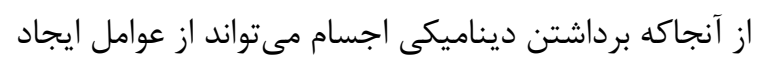

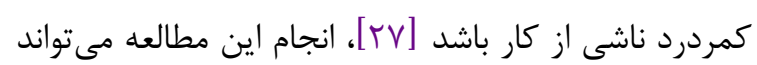

نتايج مطالعهُ حاضر با اين دو مطالعه همسو است كه آثار

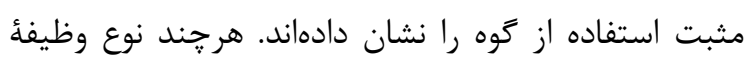

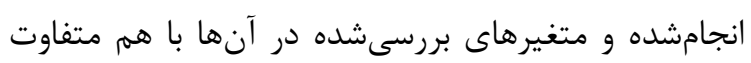

هستند.

Kongsgaard عضلات جهارسر ران و خستخى زودرس آنها را در وضعيت

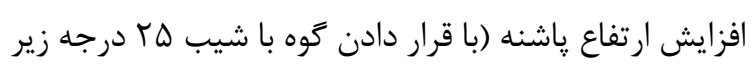

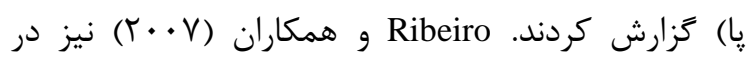
يزوهشى نشان دادهاند كه ميزان فعاليت الكتريكى عضلات

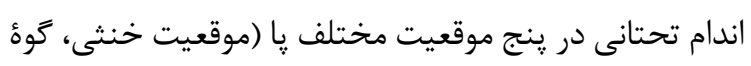

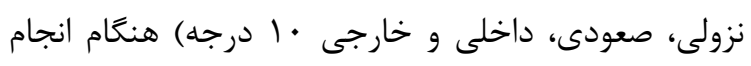

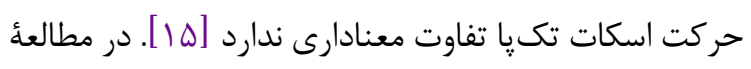
Barber

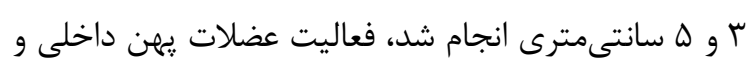

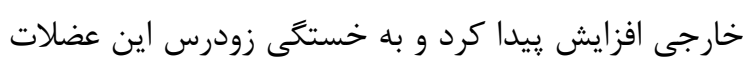

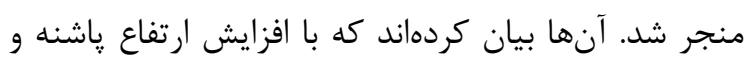

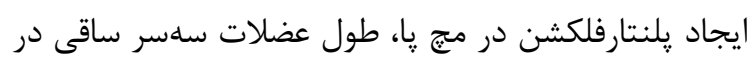

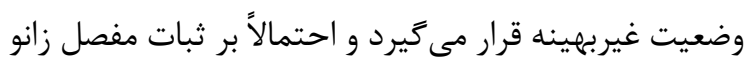

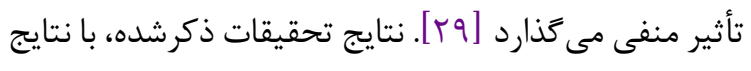
يزوهش حاضر در تضاد است. نتايج تحقيق حاضر، كاهش

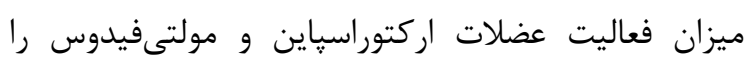

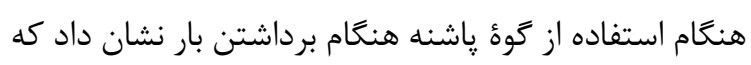

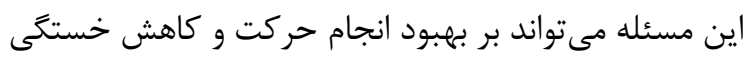
ناحيئ كمر دلالت داشته باشد. با اينحال، نتايج تحقيقات

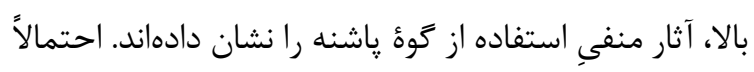
بررسى عضلات گوناگون (عضلات ناحيئ اندام تحتانى در برابر

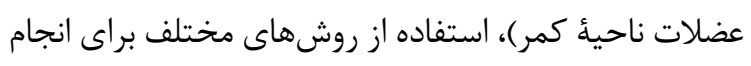

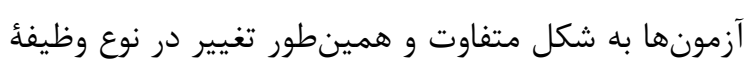

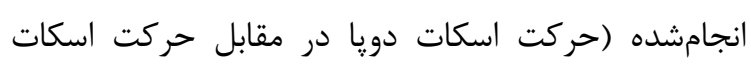
تكىٍا) باعث ايجاد اين تناقضات شدهاند. Trifimow كردهاند كه هنغام بروز خستخى عضلات جهارسر ران، زاوئ فلكشن و كشتاور در صفحهٔ ساجيتال مفصل زانو كاهش و وردان سرعت زاويهاى تنه افزايش مىيابد و فرد تكنيك برداشتن

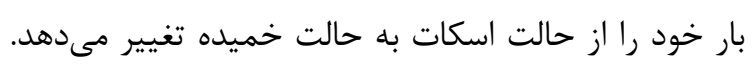

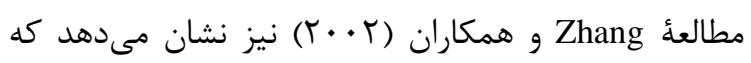
ضعف عضلات جهارسر ران باعث تغيير تكنيك ليفت شد و افراد با كاهش فلكشن زانوى خود سعى در برداشتن بار 


$$
\begin{aligned}
& \text { كاهش دهد. اين مسئله احتمالاً باعث ديرتر خسته شدنِ اين } \\
& \text { عضلات، بهبود تكنيك حركتى فرد و افزايش بازده كارى در }
\end{aligned}
$$

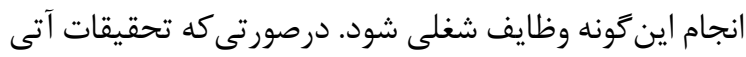

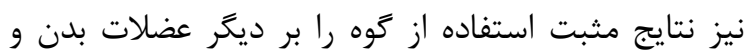

$$
\begin{aligned}
& \text { متغيرهاى كينماتيكى و كينتيكى نشان دهد، از نتايج } \\
& \text { بلهستآمده در اين يزوهش مىتوان در طراحى كفش برى براى } \\
& \text { محيطهاى شغلى و ورزشى يارى جست. } \\
& \text { تقدير و تشكر } \\
& \text { از كليه همكارانى كه در انجام اين :زوهش ما را يارى }
\end{aligned}
$$

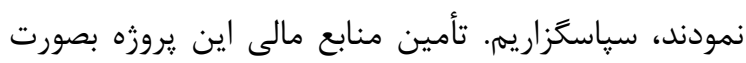

$$
\begin{aligned}
& \text { شخصى گَزارش گرديده است. } \\
& \text { تعارض منافع }
\end{aligned}
$$

بين نويسند

\section{References}

1. Lin CJ, Wang SJ, Chen HJ. A field evaluation method for assessing whole body biomechanical joint stress in manual lifting tasks. Ind Health. 2006;44(4):604-12. https://doi.org/10.2486/indhealth.44.604 PMID: 17085922

2. Sterud T, Tynes T. Work-related psychosocial and mechanical risk factors for low back pain: a 3-year follow-up study of the general working population in Norway. Occup Environ Med. 2013;70(5):296-302. https://doi.org/10.1136/oemed-2012-101116 PMID:23322920

3. Nordin MA. Musculoskeletal disorder in the workplace. Louis. Mosby; 1997.

4. Coenen P, Gouttebarge V, van der Burght AS, van Dieën JH, Frings-Dresen MH, van der Beek AJ et al. The effect of lifting during work on low back pain: a health impact assessment based on a meta-analysis. Occup Environ Med. 2014;71(12):871-7. https://doi.org/10.1136/oemed-2014-102346 PMID:25165395

5. Rohlmann A, Pohl D, Bender A, Graichen F, Dymke J, Schmidt $\mathrm{H}$ et al. Activities of everyday life with high spinal loads. PLoS One. 2014;9(5):e98510. https://doi.org/10.1371/journal.pone.0098510 PMID:24866883

6. Webster BS, Snook SH. The cost of workers compensation low back pain claims. J Occup Med. 1990;32(1):13-5. https://doi.org/10.1097/00043764199001000-00007 PMID:2139114
براى شناسايى و جلوگيرى از وضعيتهاى خطرزا سودمند

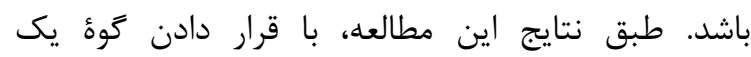

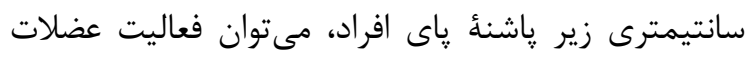

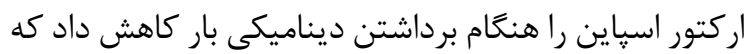

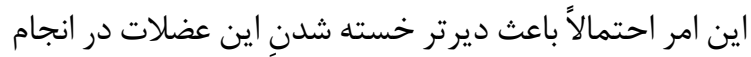
اين گونه وظايف شغلى مىشود. كاهش فعاليت اين عضلات

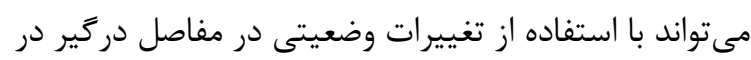
هنگام اجراى حركت اتفاق بيافتد. درنتيجه با استفاده از

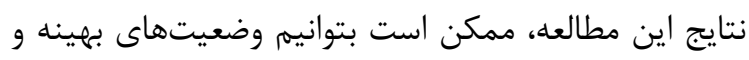
غير بهينه مفاصل مج يا را حين برداشتن بار شناسايى و به منه افراد دركير در اين نوع مشاغل توصيه كنيه.

بنا بر نتايج اين مطالعه، استفاده از گوهُ ياشنه مئوتواند

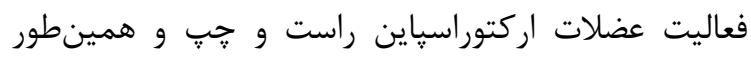
عضلئ مولتىفيدوس راست را هنگام برداشتن ديناميكى بار

7. Martimo KP, Verbeek J, Karppinen J, Furlan AD, Takala EP, Kuijer PP et al. Effect of training and lifting equipment for preventing back pain in lifting and handling: systematic review. BMJ. 2008;336(7641):429-31. https://doi.org/10.1136/bmj.39463.418380.BE PMID:18244957

8. Soares DP, de Castro MP, Mendes E, Machado L. Influence of wedges on lower limbs' kinematics and net joint moments during healthy elderly gait using principal component analysis. Hum Mov Sci. 2014;38:319-30. https://doi.org/10.1016/j.humov. 2014.09.007 PMID:25457428

9. Samimi H, Anbarian M, Kersting UG. The effect of foot wedges on postural sway and lower limb Muscle activity. International Journal of Sport Studies. 2014;4(12):1442-9.

10. Murley GS, Landorf KB, Menz HB, Bird AR. Effect of foot posture, foot orthoses and footwear on lower limb muscle activity during walking and running: a systematic review. Gait Posture. 2009;29(2):172-87. https://doi.org/10.1016/j.gaitpost.2008.08.015 PMID: $\underline{18922696}$

11. Van Gheluwe B, Dananberg HJ. Changes in plantar foot pressure with in-shoe varus or valgus wedging. J Am Podiatr Med Assoc. 2004;94(1):1-11. https://doi.org/10.7547/87507315-94-1-1 PMID:14729985

12. Murray N, Cipriani D, O'Rand D, Reed-Jones R. Effects of Foot Position during Squatting on the Quadriceps Femoris: An Electromyographic Study. Int J Exerc Sci. 2013;6(2):114-25. PMID:27293497 
13. Sato K, Fortenbaugh D, Hydock DS. Kinematic changes using weightlifting shoes on barbell back squat. J Strength Cond Res. 2012;26(1):28-33. https://doi.org/10.1519/JSC.0b013e318218dd64 PMID:22201687

14. Edwards L, Dixon J, Kent JR, Hodgson D, Whittaker VJ. Effect of shoe heel height on vastus medialis and vastus lateralis electromyographic activity during sit to $\begin{array}{lll}\text { stand. J Orthop Surg. 2008;3(2):2. } & \text { J }\end{array}$ https://doi.org/10.1186/1749-799X-3-2 PMID:18186937

15. Ribeiro G, Dionísio V, Almeida G. Electromyographic activity during one-legged squatting under different foot position. Rev Bras Med Esporte. 2007;13:36-9.

16. Hung YJ, Gross MT. Effect of foot position on electromyographic activity of the vastus medialis oblique and vastus lateralis during lower-extremity weight-bearing activities. J Orthop Sports Phys Ther. 1999;29(2):93-102.

https://doi.org/10.2519/jospt.1999.29.2.93 PMID:10322584

17. Labaj A, Diesbourg T, Dumas G, Plamondom A, Mercheri A, Larue C. Posture and lifting exposures for daycare workers. Int J Ind Ergon. 2016;54:83-92. https://doi.org/10.1016/j.ergon.2016.05.003.

18. Kim M, Yoo WG. Effects of Various Foot Wedge Boards on Vastus Medialis Oblique and Vastus Lateralis Muscles during Lunge Exercise. J Phys Ther Sci. 2013;25(3):233-4. https://doi.org/10.1589/jpts. $\underline{25.233}$.

19. Frohm A, Halvorsen K, Thorstensson A. Patellar tendon load in different types of eccentric squats. Clin Biomech (Bristol, Avon). 2007;22(6):704-11. https://doi.org/10.1016/j.clinbiomech.2006.12.006 PMID:17499407

20. Guiry M. Comparisons of an overhead and single leg squat in barefoot, minimalist, and shod conditions, in Northridge [MSc Thesis] California state university; 2014.

21. Kongsgaard M, Aagaard P, Roikjaer S, Olsen D, Jensen $\mathrm{M}$, Langberg $\mathrm{H}$ et al. Decline eccentric squats increases patellar tendon loading compared to standard eccentric squats. Clin Biomech (Bristol, Avon). 2006;21(7):748 54. https://doi.org/10.1016/j.clinbiomech.2006.03.004 PMID:16675081

22. Hamill J, Knutzen KM. Biomechanical Basis of Human Movement. $3^{\text {rd }}$ ed. 2009.

23. Yeung S, Genaidy A, Deddens J, Shoaf C, Leung PC. A participatory approach to the study of lifting demands and musculoskeletal symptoms among Hong Kong workers. Occup Environ Med. 2003;60(10):730-8. https://doi.org/10.1136/oem.60.10.730 PMID:14504360

24. Abdoli-E M, Stevenson JM. The effect of on-body lift assistive device on the lumbar 3D dynamic moments and EMG during asymmetric freestyle lifting. Clin Biomech (Bristol, Avon). 2008;23(3):372-80. https://doi.org/10.1016/j.clinbiomech.2007.10.012 PMID:18093709
25. Hermens HJ, Freriks B, Disselhorst-Klug C, Rau G. Development of recommendations for SEMG sensors and sensor placement procedures. J Electromyogr Kinesiol. 2000;10(5):361-74. https://doi.org/10.1016/S1050-6411(00)00027-4 PMID:11018445

26. Felson DT, Gross KD, Nevitt MC, Yang M, Lane NE, Torner JC et al. The effects of impaired joint position sense on the development and progression of pain and structural damage in knee osteoarthritis. Arthritis Rheum. 2009;61(8):1070-6. https://doi.org/10.1002/ art.24606 PMID:19644911

27. Kingma I, Baten CT, Dolan P, Toussaint HM, van Dieën JH, de Looze MP et al. Lumbar loading during lifting: a comparative study of three measurement techniques. J Electromyogr Kinesiol. 2001;11(5):33745. https://doi.org/10.1016/S1050-6411(01)00011-6 PMID:11595553

28. Cè E, Rampichini S, Agnello L, Limonta E, Veicsteinas A, Esposito F. Combined effects of fatigue and temperature manipulation on skeletal muscle electrical and mechanical characteristics during isometric contraction. J Electromyogr Kinesiol. 2012;22(3):34855. $\quad$ https://doi.org/10.1016/j.jelekin.2012.01.012 PMID:22353336

29. Barber LA, Barrett RS, Gillett JG, Cresswell AG, Lichtwark GA. Neuromechanical properties of the triceps surae in young and older adults. Exp Gerontol. 2013;48(11):1147-55. https://doi.org/10.1016/j.exger.2013.07.007 PMID:23886750

30. Roy SH, Bonato P, Knaflitz M. EMG assessment of back muscle function during cyclical lifting. J Electromyogr Kinesiol. 1998;8(4):233-45. https://doi.org/10.1016/S1050-6411(98)00010-8 PMID:9779397 